\title{
Liver $X$ receptors preserve renal glomerular integrity under normoglycaemia and in diabetes in mice
}

\author{
Monika Patel • Xiaoxin X. Wang • Lilia Magomedova • Rohan John • Adil Rasheed • \\ Hannah Santamaria • Weidong Wang • Ricky Tsai • Liru Qiu • Arturo Orellana • \\ Andrew Advani • Moshe Levi • Carolyn L. Cummins
}

Received: 17 July 2013 / Accepted: 1 October 2013 / Published online: 8 November 2013

(C) Springer-Verlag Berlin Heidelberg 2013

\begin{abstract}
Aims/hypothesis Liver X receptors (LXRs) $\alpha$ and $\beta$ are nuclear hormone receptors that are widely expressed in the kidney. They promote cholesterol efflux from cells and inhibit inflammatory responses by regulating gene transcription. Here, we hypothesised (1) that LXR deficiency would promote renal decline in a mouse model of diabetes by accelerating intraglomerular cholesterol accumulation and, conversely, (2) that LXR agonism would attenuate renal decline in diabetes.
\end{abstract}

Electronic supplementary material The online version of this article (doi:10.1007/s00125-013-3095-6) contains peer-reviewed but unedited supplementary material, which is available to authorised users.

M. Patel $\cdot$ L. Magomedova $\cdot$ A. Rasheed $\cdot$ R. Tsai $\cdot$

C. L. Cummins $(\square)$

Faculty of Pharmacy, University of Toronto, 144 College St,

Toronto, ON M5S 3M2, Canada

e-mail: carolyn.cummins@utoronto.ca

X. X. Wang $\cdot$ H. Santamaria $\cdot$ W. Wang $\cdot$ L. Qiu $\cdot$ M. Levi

Division of Renal Diseases and Hypertension, Department of

Medicine, University of Colorado, Aurora, CO, USA

X. X. Wang $\cdot$ H. Santamaria $\cdot$ W. Wang $\cdot$ L. Qiu $\cdot$ M. Levi

VA Medical Center, Denver, CO, USA

R. John

Department of Pathology, University Health Network, Toronto, ON, Canada

A. Orellana

Department of Chemistry, York University, Toronto, ON, Canada

A. Advani

Keenan Research Centre of the Li Ka Shing Knowledge Institute,

St. Michael's Hospital, Toronto, ON, Canada

A. Advani · C. L. Cummins

Banting and Best Diabetes Centre, Toronto, ON, Canada
Methods Diabetes was induced with streptozotocin (STZ) and maintained for 14 weeks in $\operatorname{Lxr} \alpha / \beta^{+/+}(\operatorname{Lx} r \alpha$, also known as $N r 1 h 3 ; \operatorname{Lxr} \beta$, also known as $N r 1 h 2)$ and $L x r \alpha / \beta^{-/}$mice. In addition, STZ-injected DBA/2J mice were treated with vehicle or the LXR agonist $N, N$-dimethyl-hydroxycholenamide (DMHCA) (80 mg/kg daily) for 10 weeks. To determine the role of cholesterol in diabetic nephropathy (DN), mice were placed on a Western diet after hyperglycaemia developed.

Results Even in the absence of diabetes, $L x r \alpha / \beta^{-/}$mice exhibited a tenfold increase in the albumin:creatinine ratio and a 40-fold increase in glomerular lipid accumulation compared with $\operatorname{Lxr} \alpha / \beta^{+/+}$mice. When challenged with diabetes, $\operatorname{Lxr} \alpha / \beta^{-/}$mice showed accelerated mesangial matrix expansion and glomerular lipid accumulation, with upregulation of inflammatory and oxidative stress markers. In the DN-sensitive STZ DBA/2J mouse model, DMHCA treatment significantly decreased albumin and nephrin excretion (by 50\% each), glomerular lipids and plasma triacylglycerol (by 70\%) and cholesterol (by 48\%); it also decreased kidney inflammatory and oxidative stress markers compared with vehicle-treated mice.

Conclusions/interpretation These data support the idea that LXR plays an important role in the normal and diabetic kidney, while showing that LXR, through its inhibitory effect on inflammation and cholesterol accumulation in glomeruli, could also be a novel therapeutic target for DN.

Keywords Cholesterol - Diabetic nephropathy - DMHCA · $\mathrm{LDL} \cdot$ Liver $\mathrm{x}$ receptor
Abbreviations
ABC ATP-binding cassette
ABCA1 ABC transporter A1
ABCG1 ABC transporter G1
ACR Albumin:creatinine ratio
DMHCA $\quad N, N$-Dimethyl-hydroxycholenamide 


$\begin{array}{ll}\text { DN } & \text { Diabetic nephropathy } \\ \text { LC } & \text { Liquid chromatography } \\ \text { LXR } & \text { Liver x receptor } \\ \text { MDA } & \text { Malondialdehyde } \\ \text { MS } & \text { Mass spectrometry } \\ \text { NOX } & \text { NADPH oxidase } \\ \text { OLR1 } & \text { Oxidised-LDL receptor } \\ \text { Ox-LDL } & \text { Oxidised-LDL } \\ \text { PAS } & \text { Periodic acid-Schiff's reagent } \\ \text { RAS } & \text { Renin-angiotensin system } \\ \text { SREBP1c } & \text { Sterol regulatory element-binding protein 1c } \\ \text { STZ } & \text { Streptozotocin }\end{array}$

\section{Introduction}

Diabetic nephropathy (DN) is the leading cause of end-stage renal disease, accounting for $44 \%$ of new cases each year [1]. Hyperglycaemia and hypertension are established causes of DN; however, elevated plasma lipids are also linked with progression to microalbuminuria [2]. Several investigators have hypothesised that lipids play a causal role in the progression of chronic kidney disease, noting the similarities between the pathogenesis of atherosclerosis and glomerulosclerosis. These include: influx of monocytes, build-up of lipid-laden cells, and the presence of cholesterol and cholesteryl esters [3-5]. Several cross-sectional studies of patients with type 1 diabetes have indicated that elevated apolipoprotein B or LDL-cholesterol and/or decreased levels of HDL-cholesterol are associated with progression of albuminuria [6-10]. Moreover, experiments in animal models of diabetes fed a Western diet have also supported the notion that sustained lipid abnormalities accelerate the progression of DN [11-14].

The liver X receptors (LXRs) $\alpha$ and $\beta$ are nuclear hormone receptors. They are activated by endogenous oxysterols, which are natural products derived from the metabolism of cholesterol. LXRs are considered to be intracellular 'cholesterol sensors' because they activate transcription in response to cholesterol metabolites [15]. LXR activation by a synthetic ligand was atheroprotective in animal models of dyslipidaemia [16]. Mechanistically, this atheroprotective effect has been attributed to enhanced reverse cholesterol transport and inhibition of inflammatory responses upon LXR activation $[16,17]$. Direct LXR target genes include those encoding the ATP-binding cassette $(\mathrm{ABC})$ transporter $\mathrm{A} 1 \mathrm{ABCA} 1)$ and the $\mathrm{ABC}$ transporter $\mathrm{G} 1$ (ABCG1), which govern cholesterol efflux from macrophages and peripheral organs, and the inducible degrader of LDL receptor (Idol [also known as Mylip]), which decreases LDL receptor protein levels and peripheral cholesterol uptake $[18,19]$. In macrophages, LXR activation inhibits the expression of inflammatory cytokines (i.e. IL-1 $\beta$, IL-6 and TNF $\alpha$ ) [20, 21], monocyte chemoattractant protein and osteopontin [22]. Unfortunately, first-generation LXR agonists (T0901317, GW3965) caused hypertriacylglycerolaemia through upregulation of hepatic sterol regulatory element-binding protein 1c (SREBP1c) [23]. $N, N$-Dimethyl-hydroxycholenamide (DMHCA) is a new-generation LXR gene-selective agonist, which reduces plaque formation in animal models of atherosclerosis without inducing hypertriacylglycerolaemia [24, 25].

Human biopsies and experimental rodent models have revealed a consistent downregulation of LXRs in DN compared with control $[26,27]$, and experiments with firstgeneration LXR ligands have shown anti-inflammatory and anti-albuminuric actions in diabetic mice [28,29]. While these observations are promising for the development of DN therapies targeting LXRs, several fundamental questions remain. First, whereas LXR agonism may slow renal decline, the effects of LXR downregulation (as observed in patients) on the natural progression of renal decline are unknown. Second, although LXRs appear to prevent inflammation within the renal tubulointerstitium, the role of these receptors in preserving glomerular homeostasis is incompletely defined, considering the importance of glomerular injury in the pathogenesis of DN and the broad range of LXR target genes. Finally, while first-generation LXR agonists have provided proof of concept for the biological importance of this pathway in DN, they are not clinical drug candidates because of their undesirable effects on plasma and liver triacylglycerol levels. To address these deficiencies, we performed experiments in $L x r \alpha / \beta^{-/-}$( $L x r \alpha$, also known as Nr1h3; Lxr $\beta$, also known as $N r 1 h 2)$ mice and in mice treated with a new-generation LXR ligand, DMHCA. We hypothesised that $L x r \alpha / \beta^{-/-}$mice (which lack the ability to regulate intracellular cholesterol) would have hastened progression of DN and, conversely, that activation of LXR would protect against DN through improved renal cholesterol homeostasis and inhibition of inflammatory activators. Here, we present our data outlining the important role of LXR in modifying intraglomerular lipid accumulation in the context of DN.

\section{Methods}

Animals All animal procedures were performed in compliance with the Principles of Laboratory Animal Care (NIH publication number 85-23, revised 1985; http://grants1.nih. gov/grants/olaw/references/phspol.htm) and were approved by the Institutional Animal Care Committees at the Universities of Toronto and Colorado. To avoid the confounding effects of insulin on lipogenesis, we explored the role of LXR in insulinopenic models of DN induced by streptozotocin (STZ). For the first animal model, based on $L x r \alpha / \beta^{--}$mice with STZinduced diabetes, we used male $L x r \alpha / \beta^{--}$and matching wild-type mice (C57B1/6:129SvEv) [30], which were maintained on chow (2016 Teklad Global rodent diet; Harlan 
Teklad, Mississauga, ON, Canada). At 8 weeks, mice were given daily i.p. injections of STZ (Sigma-Aldrich, Oakville, ON, Canada) or vehicle (citrate) $\left(\operatorname{Lxr} \alpha / \beta^{+/+}\right.$ $50 \mathrm{mg} / \mathrm{kg} ; \operatorname{Lxr} \alpha / \beta^{-/} 35 \mathrm{mg} / \mathrm{kg}$ ) for 5 consecutive days. All mice were switched to a Western $\operatorname{diet}(21 \% \mathrm{wt} / \mathrm{wt}$ milk fat, $0.2 \% \mathrm{wt} / \mathrm{wt}$ cholesterol) (TD88137; Harlan Teklad) at 1 week after injections had started, and followed for 14 weeks. The second animal model was based on DBA/2J mice with STZinduced diabetes. We chose DBA/2J male mice (Jackson Laboratories, Bar Harbor, ME, USA) because they are more prone to developing $\mathrm{DN}$ and do so at an earlier age than $\mathrm{C} 57 \mathrm{Bl} / 6$ mice $[31,32]$. At 8 weeks, these mice were treated with $40 \mathrm{mg} / \mathrm{kg} \mathrm{STZ}$ or vehicle (citrate) for 5 consecutive days and then placed on a Western diet (TD88137) containing vehicle or the LXR agonist DMHCA ( $80 \mathrm{mg} / \mathrm{kg}$ daily) for 10 additional weeks (see electronic supplementary material [ESM] Methods).

Urine and plasma analyses Blood was collected into EDTAcoated tubes and plasma was analysed using commercially available assays (see ESM Methods for further details).

Histology and immunofluorescence One kidney was sectioned for paraffin embedding (fixed in formalin), optimal cutting temperature compound (OCT) embedding (fixed in formalin then sucrose-protected in a $10 \% \mathrm{wt} / \mathrm{vol}$. and $30 \% \mathrm{wt} / \mathrm{vol}$. sucrose solution) and electron microscopy (fixed in glutaraldehyde). See ESM Methods for details on staining and quantification.

Kidney lipid analysis Tissues were digested in chloroform : methanol (2:1) with a 20:1 volume to tissue ratio, and processed as described previously [30].

RNA isolation and gene expression analysis RNA was isolated and cDNA synthesised as described previously [30]. Gene expression levels were measured by high-throughput real-time quantitative PCR (7900HT; Applied Biosystems, Foster City, CA, USA) using the $2^{-\Delta \Delta \mathrm{C}_{\mathrm{t}}}$ method and normalised to cyclophilin. Primer sequences are given in ESM Table 1.

DMHCA liquid chromatography and mass spectrometry analysis Dried kidney lipid extracts were re-suspended in $250 \mu \mathrm{l}$ HPLC-grade methanol and analysed by liquid chromatography (LC) and mass spectrometry (MS) using a device (6410 Triple Quad LC/MS; Agilent Technologies, Santa Clara, CA, USA) with the electrospray ionisation source in positive ion mode (details, see ESM Methods).

Western blot analysis Protein extracts $(80 \mu \mathrm{g})$ from kidney cortex were separated by SDS-PAGE and transferred to polyvinylidene difluoride membranes or nitrocellulose membrane (ABCA1 only) (see ESM Methods for further details).
Statistical analysis ANOVA was used for comparisons between all groups, followed by Student-Newman-Keuls tests. The sample size for each group represents the number of animals that survived until the end of the treatment period, unless otherwise stated. All values are expressed as mean \pm SEM; a value of $p<0.05$ was considered statistically significant (see ESM Methods and ESM Table 2 for details).

\section{Results}

LXR deficiency increased the severity of diabetic kidney disease To assess the role of LXR and cholesterol accumulation in the progression of DN, we induced diabetes in $L x r \alpha / \beta^{+/+}$and $L x r \alpha / \beta^{-/}$mice using STZ and a Western diet. Both STZtreated groups were hyperglycaemic, with $L x r \alpha / \beta^{+/+}$mice achieving $15 \%$ higher glucose levels than $L x r \alpha / \beta^{-/-}$mice (Table 1). After 14 weeks, diabetic $\operatorname{Lx} \alpha \alpha / \beta^{+/+}$mice had twofold higher levels of albuminuria than non-diabetic controls (Fig. 1a). Remarkably, non-diabetic $L x r \alpha / \beta^{-/}$mice had a tenfold higher albumin : creatinine ratio (ACR) than $L x r \alpha / \beta^{+/+}$ mice, with no further increase observed following STZ administration in $L x r \alpha / \beta^{-/-}$mice (Fig. 1a). In contrast, urinary nephrin excretion was significantly increased in STZ Lxr $\alpha / \beta^{-/}$mice compared with matching normoglycaemic mice, suggesting that structural features of renal pathology were worsened with hyperglycaemia in $L x r \alpha / \beta^{-/}$mice (Fig. 1b). Synaptopodin showed decreased staining in Lxr $\alpha / \beta^{+/+}$STZ-treated animals and $L x r \alpha / \beta^{-/-}$mice compared with the wild-type control group (Fig. 1c). These data suggest that $L x r \alpha / \beta^{-/}$mice on a Western diet have an impaired glomerular filtration barrier compared with $L x r \alpha / \beta^{+/+}$mice, and that this impairment is further exacerbated by diabetes.

Diabetic Lxr $\alpha / \beta^{-/}$mice showed increased neutral lipid accumulation in glomeruli compared with wild-type mice despite their similar circulating cholesterol levels To determine whether the severity of DN correlated with renal lipid accumulation, we analysed kidney sections by histology and measured bulk lipids after organic extraction. Oil Red $\mathrm{O}$ staining for neutral lipids was primarily in the glomeruli, with sporadic staining in the tubulointerstitial region of STZ $L x r \alpha / \beta^{-/}$mice (Fig. 1d, ESM Fig. 1). Image analysis showed a 41-fold higher level of staining in non-diabetic $L x r \alpha / \beta^{-/-}$mice than in $L x r \alpha / \beta^{+/+}$ mice, and this was further increased by twofold after STZ treatment (Fig. 1e). Total kidney cholesterol was higher in $L x r \alpha / \beta^{-/}$mice, while triacylglycerol tended to be lower, but there were no significant differences between groups (Table 1). Plasma cholesterol levels remained constant in all treatment groups and plasma triacylglycerol levels were lower in Lxr $\alpha / \beta^{-/-}$than in $\operatorname{Lxr} \alpha / \beta^{+/+}$mice (Table 1). 
Table 1 Physiological variables for non-diabetic and diabetic $L x r \alpha / \beta^{+/+}$and $L x r \alpha / \beta^{-/-}$ mice

${ }^{\mathrm{a}}$ From 8 to 20 weeks of age ${ }^{*} p<0.05$ for difference from vehicle-treated animals of the same genotype

${ }^{\dagger} p<0.05$ for difference from Lxr $\alpha / \beta^{+/+}$animals of the same treatment group

\begin{tabular}{|c|c|c|c|c|}
\hline \multirow[t]{2}{*}{ Variable } & \multicolumn{2}{|l|}{$\operatorname{Lxr} \alpha / \beta^{+/+}$} & \multicolumn{2}{|l|}{$\operatorname{Lxr} \alpha / \beta^{-/-}$} \\
\hline & Vehicle & $\mathrm{STZ}$ & Vehicle & STZ \\
\hline$n$ & 6 & 6 & 6 & 3 \\
\hline Plasma glucose (mmol/l) & $6.5 \pm 0.4$ & $30 \pm 2 *$ & $6.8 \pm 0.7$ & $26 \pm 2 * \dagger$ \\
\hline Plasma triacylglycerol (mmol/l) & $1.5 \pm 0.2$ & $1.5 \pm 0.3$ & $0.8 \pm 0.1$ & $0.42 \pm 0.09$ \\
\hline Plasma cholesterol (mmol/1) & $7.4 \pm 0.4$ & $7.6 \pm 0.5$ & $7.3 \pm 0.4$ & $7.5 \pm 0.4$ \\
\hline Plasma ox-LDL (mmol/l) & $1.9 \pm 0.2$ & $1.9 \pm 0.1$ & $2.1 \pm 0.5$ & $2.6 \pm 0.7$ \\
\hline Kidney cholesterol (mg/g) & $3.8 \pm 0.3$ & $4.0 \pm 0.3$ & $5.1 \pm 0.4^{\dagger}$ & $5.3 \pm 0.3^{\dagger}$ \\
\hline Kidney triacylglycerol (mg/g) & $30 \pm 9$ & $17 \pm 7$ & $9 \pm 3$ & $15 \pm 5$ \\
\hline Final body weight (g) & $37 \pm 2$ & $31 \pm 2 *$ & $35 \pm 1$ & $29 \pm 1$ \\
\hline Increase in bodyweight $(\mathrm{g})^{\mathrm{a}}$ & $13 \pm 2$ & $3 \pm 2 *$ & $6 \pm 3^{\dagger}$ & $3 \pm 1$ \\
\hline Kidney weight (g) & $0.36 \pm 0.02$ & $0.38 \pm 0.01^{*}$ & $0.46 \pm 0.02^{\dagger}$ & $0.44 \pm 0.03$ \\
\hline Kidney:body weight ratio \% (g:g) & $0.90 \pm 0.03$ & $1.24 \pm 0.08^{*}$ & $1.34 \pm 0.05^{\dagger}$ & $1.53 \pm 0.08^{\dagger}$ \\
\hline Water intake $\left(\mathrm{ml} \mathrm{kg}^{-1} \mathrm{~h}^{-1}\right)$ & $5.5 \pm 0.6$ & $21 \pm 5^{*}$ & $11 \pm 1$ & $22 \pm 4$ \\
\hline Urine flow rate $\left(\mathrm{ml} \mathrm{kg}^{-1} \mathrm{~h}^{-1}\right)$ & $1.5 \pm 0.3$ & $19 \pm 6^{*}$ & $5.1 \pm 0.6$ & $27 \pm 6^{*}$ \\
\hline
\end{tabular}

To determine whether decreased cholesterol export contributed to the increase in glomerular lipids in $L x r \alpha / \beta^{-/}$ mice, we examined the LXR target genes Abcal and Abcgl (cholesterol efflux transporters). There was no change in the basal expression of $A b c g 1$, while $L x r \alpha / \beta^{-/}$mice had decreased mRNA levels of Abcal (ESM Fig. 2a). Western blot analysis of ABCA1, however, showed no significant difference between groups (ESM Fig. 2c). Likewise, no significant difference was observed between groups in genes important to the cholesterol biosynthetic pathway, e.g. Srebp2 (also known as Srebf2) and Hmgcr (ESM Fig. 2a). To establish whether triacylglycerol synthesis was altered, we measured the LXR target genes Srebplc (also known as Srebf1 ) and Scd1. While Srebplc expression was significantly reduced in vehicle-treated $L x r \alpha / \beta^{-/}$kidney, this baseline reduction was blunted in STZ-treated $L x r \alpha / \beta^{-/}$mice, although its relative expression still remained lower than in STZ-treated $L x r \alpha / \beta^{+/+}$mice. Scdl also showed a trend towards a baseline decrease in non-diabetic $L x r \alpha / \beta^{-/}$mice compared with $L x r \alpha / \beta^{+/+}$mice; this decrease was significantly blunted in response to STZ treatment (ESM Fig. 2a). The expression of fatty acid oxidation genes (Ppara, Acox1, Cptla) was unchanged between genotypes (ESM Fig. 2a). Taken together, these data suggest that the accumulation of neutral lipids in the glomeruli of STZ $L x r \alpha / \beta^{--}$mice compared with STZ $L x r \alpha / \beta^{+/+}$mice cannot be explained by decreased cholesterol efflux, decreased fatty acid oxidation, or increased cholesterol or triacylglycerol synthesis.

Lipoprotein uptake in the kidney is primarily mediated through the LDL receptor with some contribution from scavenger receptors [33, 34]. The scavenger receptor encoded by $C d 36$ was moderately decreased in $L x r \alpha / \beta^{--}$compared with $L x r \alpha / \beta^{+/+}$mice, but not significantly altered by diabetes
(ESM Fig. 2b). In contrast, mRNA and protein levels of the oxidised-LDL (ox-LDL) receptor (OLR1) were increased in diabetic $L x r \alpha / \beta^{--}$mice (Fig. 2a, b). With a focus on lipid uptake, we found that the expression of $I d o l$, which regulates LDL receptor expression and is an LXR target gene, was significantly decreased in $L x r \alpha / \beta^{-/}$mice (Fig. 2c) and correlated with increased LDL receptor levels in $L x r \alpha / \beta^{-/}$ mice (Fig. 2d). Electron microscopy of glomeruli from $L x r \alpha / \beta^{-/-}$mice showed increased lipid droplets after STZ treatment, these being localised to the mesangial matrix (Fig. 2e). Together, these data suggest that, although STZ Lxr $\alpha / \beta^{--}$mice have total circulating cholesterol levels similar to mice in other groups, the extensive accumulation of lipids in their glomeruli may be due to increased uptake and/or increased retention of circulating lipids.

Diabetic Lxr $\alpha / \beta^{-1}$ mice had increased markers of extracellular matrix and profibrotic growth factors compared with diabetic Lxr $\alpha / \beta^{+/+}$mice To determine whether $L x r \alpha / \beta^{-/-}$mice exhibited features of early $\mathrm{DN}$, including tubulointerstitial fibrosis and mesangial matrix protein accumulation, we analysed markers of each by histological and gene expression techniques. Periodic acid-Schiff's reagent (PAS) stained samples were blinded and analysed by a renal pathologist. Control and diabetic $L x r \alpha / \beta^{-/}$mice had areas of concentrated PAS staining indicative of mesangial matrix accumulation (Fig. 3a). Diabetic $L x r \alpha / \beta^{--}$samples had the most severe pathological changes and were the only group with hyalinotic lesions (Fig. 3b). Semiquantitative scoring of sections revealed an 18 -fold increase in mesangial matrix expansion in the diabetic $L x r \alpha / \beta^{-/}$samples compared with diabetic $L x r \alpha / \beta^{+/+}$mice and a sevenfold increase in diabetic compared with non-diabetic $L x r \alpha / \beta^{-/}$mice (Fig. 3c). Gene expression analyses showed significant increases 

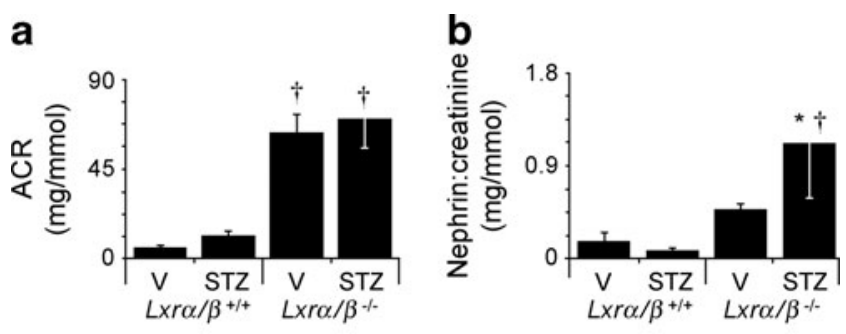

C

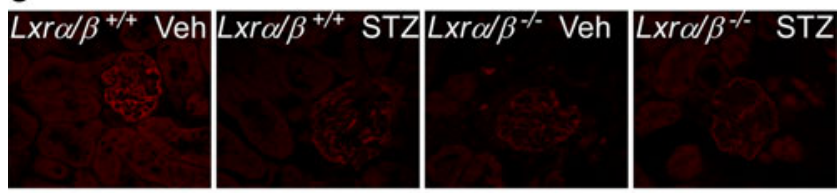

d
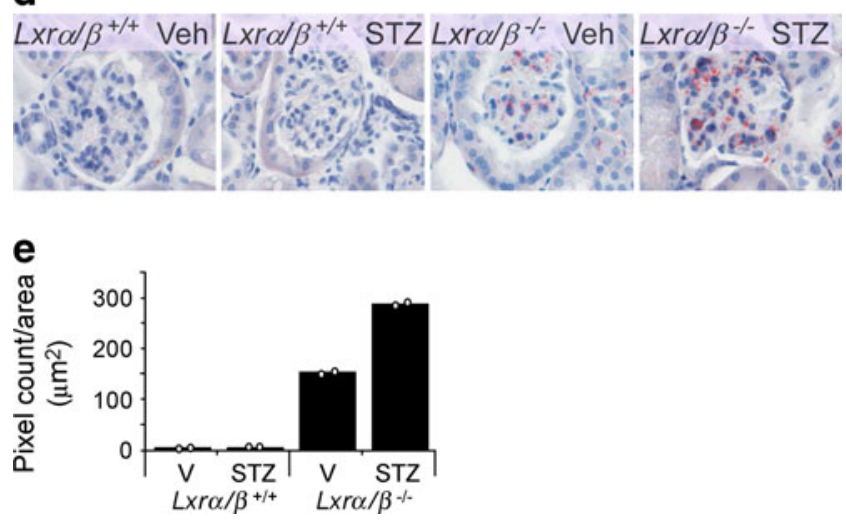

Fig. 1 Diabetic $L x r \alpha / \beta^{-/}$mice have a compromised glomerular filtration barrier. (a) Urinary ACR and (b) urinary nephrin:creatinine ratio after 14 weeks on a Western diet. V, vehicle. (c) Representative immunofluorescence staining of kidney sections for the podocyte marker synaptopodin (red) at $\times 200$ magnification. Veh, vehicle. (d) Oil Red O staining of kidney sections showing significant accumulation of neutral lipids in glomeruli of diabetic $L x r \alpha / \beta^{-/}$mice compared with diabetic Lxr $\alpha / \beta^{+/+}$mice at $\times 400$ magnification. (e) Glomerular lipid accumulation was quantified by normalising the Oil Red $\mathrm{O}$ intensity to total glomerular surface area. The bars represent the average of kidney samples from two mice (individual values are shown as white circles). A total of 25 glomeruli were quantified for each animal. Data (a, b) are means $\pm \mathrm{SEM} ; n=6$ (a), except for $\operatorname{Lxr} \alpha / \beta^{-/}(n=3) ; n=5(\mathbf{b})$, except for $L x r \alpha / \beta^{--}(n=3)$, please note that sample sizes were smaller because spot urine was not sufficient from all mice. ${ }^{*} p<0.05$ compared with vehicle control of the respective genotype and ${ }^{\dagger} p<0.05$ compared with $L x r \alpha / \beta^{+/+}$of the same treatment group, tests by one-way ANOVA and Student-Newman-Keuls

in markers of renal fibrosis, including genes contributing to the extracellular matrix, e.g. Fn1 and Colla2 (Fig. 3d, e), as well as those encoding profibrotic growth factors, e.g. $\operatorname{Tg} f \beta$ (also known as $T g f b 1$ ) and $C t g f$ (Fig. 3f, g). The TGF $\beta$ target genes, Colla 2 and Ctgf, were only significantly increased in STZ-treated $L x r \alpha / \beta^{-\digamma}$ mice, remaining unchanged in all other groups. No evidence of interstitial fibrosis was noted by histological analysis and no changes in the expression of $\alpha$-smooth muscle actin, a marker of collagen-producing myofibroblasts, were observed (data not shown).
Diabetic Lxr $/ /^{-/}$mice had elevated proinflammatory and oxidative stress markers LXRs are important determinants of inflammatory signalling. To assess local kidney inflammation, we analysed kidney sections for CD45 leucocyte staining and measured the gene expression of the inflammatory markers $T l r 2, I l 1 b, I c a m 1$ and $O p n$ (also known as $S p p 1$ ), all of which are known to be dysregulated in DN. The number of CD45 cells in the glomeruli tended to increase in STZ-treated animals compared with controls, as well as basally in $L x r \alpha / \beta^{-/}$mice compared with $L x r \alpha / \beta^{+/+}$mice (Fig. 4a, b). Consistent with these data, all inflammatory genes showed their highest expression levels in diabetic $L x r \alpha / \beta^{-/}$mice, including the macrophage marker $C d 68$ (Fig. $4 \mathrm{c}-\mathrm{g}$ ).

Oxidative stress and inflammation are highly intertwined in pathological states. A key mediator of oxidative stress is the multiprotein NADPH oxidase (NOX) system. NOX2 and its functional partner $\mathrm{p} 47^{\text {phox }}$ are critical for the progression of DN. Consistent with an increased inflammatory response, a

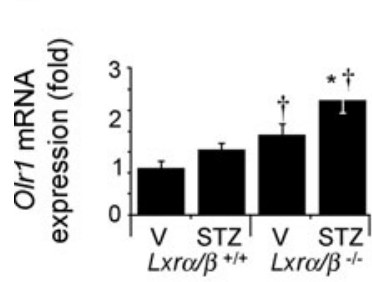

C

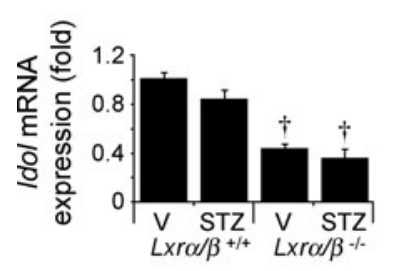

b

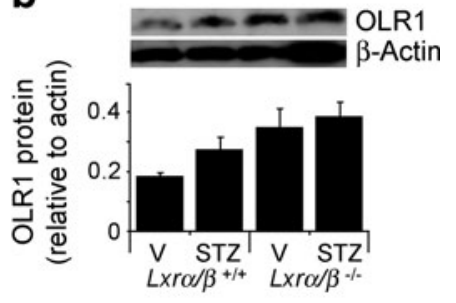

d

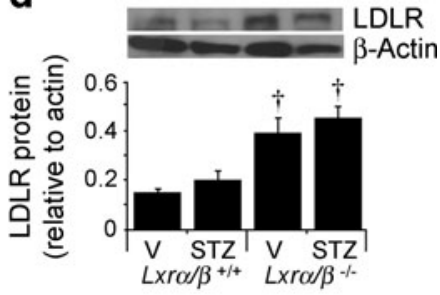

e

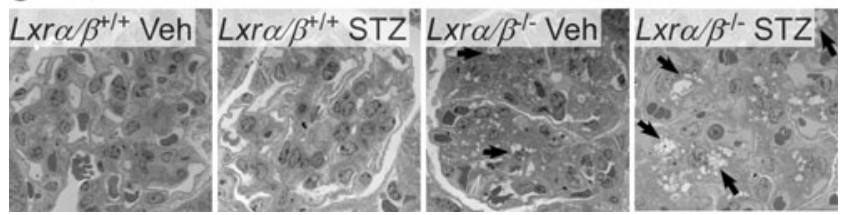

Fig. 2 Diabetic $L x r \alpha / \beta^{-/}$glomeruli have increased lipid accumulation in the mesangium. (a) Kidney gene expression and (b) protein levels of OLR1, an oxidised cholesterol uptake receptor. (c) Kidney expression of Idol (inducible degrader of the LDL receptor [LDLR]) and (d) kidney protein levels of the LDL receptor. Total protein $(\mathbf{b}, \mathbf{d})$ was normalised to $\beta$-actin. V, vehicle. (e) Electron micrographs of glomeruli at $\times 800$ magnification. Normal glomeruli without lipid droplets were found in $L x r \alpha / \beta^{+/+}$Veh and $L x r \alpha / \beta^{+/+}$STZ mice. Increasing numbers of lipid droplets were observed in $L x r \alpha / \beta^{-1-}$ Veh and $L x r \alpha / \beta^{-1}$ STZ mice (changes highlighted by arrows). Veh, vehicle. Data (a-d) are means \pm SEM; $n=6$, except for $L x r \alpha / \beta^{-/-}(n=3) ;{ }^{*} p<0.05$ compared with vehicle control of the respective genotype and ${ }^{\dagger} p<0.05$ compared with $L x r \alpha / \beta^{+/+}$of the same treatment group, tests by one-way ANOVA and Student-Newman-Keuls 
a
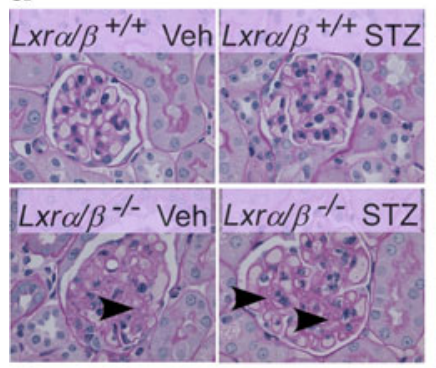

b

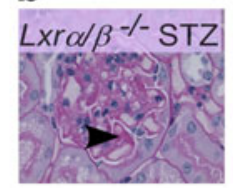

C

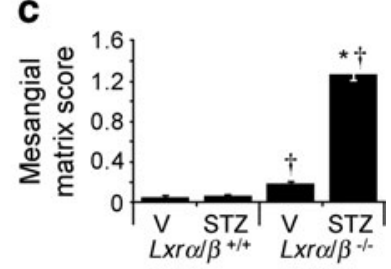

d

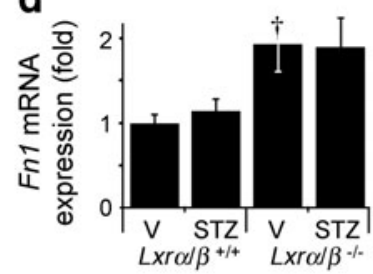

f

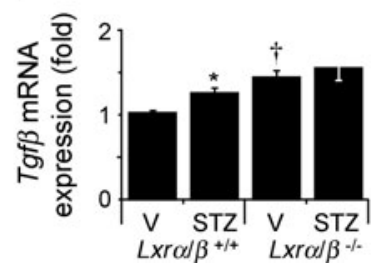

e

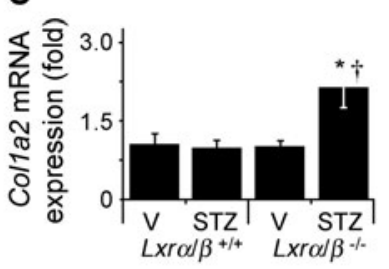

g

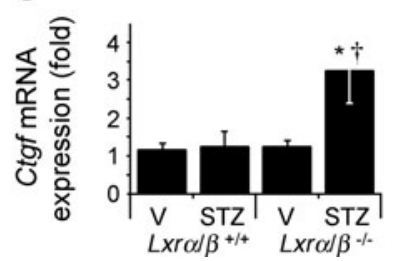

Fig. 3 Diabetic $L x r \alpha / \beta^{--}$mice have increased mesangial matrix expansion compared with diabetic $L x r \alpha / \beta^{+/+}$mice. (a) PAS staining at $\times 400$ magnification showing normal glomeruli $\left(L x r \alpha / \beta^{+/ 4}\right.$ vehicletreated [Veh] and $L x r \alpha / \beta^{+/+}$STZ-treated). $L x r \alpha / \beta^{-/-}$vehicle-treated mice had an increase in loose-appearing mesangium and occasional PAS-positive mesangial matrix; Lxr $\alpha / \beta^{-/-}$STZ-treated mice had prominently increased matrix. Arrowheads indicate changes. (b) Additional PAS staining of $L x r \alpha / \beta^{-/}$STZ glomeruli showing strong matrix staining with areas of hyalinotic lesions (arrow). (c) Semiquantitative analysis of mesangial matrix expansion in $\sim 100$ glomeruli per mouse $(n=3-4)$. (d) Kidney expression of genes encoding extracellular matrix proteins, i.e. Fn1 and (e) Colla2, and (f) of genes encoding the profibrotic growth factors TGF $\beta$ and connective tissue growth factor (CTGF). Data (c-g) are means \pm SEM: $n=6$, except for Lxr $\alpha / \beta^{-/}(n=3)$ and quantification of mesangial matrix expansion in (c); $* p<0.05$ compared with vehicle $(\mathrm{V})$ control of the respective genotype and ${ }^{\dagger} p<0.05$ compared with $L x r \alpha / \beta^{+/+}$of the same treatment group, tests by one-way ANOVA and Student-Newman-Keuls

Nox2 (also known as $C y b b$ ) and $p 47^{\text {phox }}$ (also known as $N c f 1$ ) were elevated in $L x r \alpha / \beta^{-/}$mice compared with their $L x r \alpha / \beta^{+/+}$counterparts (Fig. 4h, i). Physiologically, oxidative stress can result in increased lipid peroxidation. As a surrogate marker, we measured malondialdehyde (MDA) and found a significant increase in urinary MDA in STZ $L x r \alpha / \beta^{+/+}$and $L x r \alpha / \beta^{--}$animals compared with non-diabetic controls. Furthermore, non-diabetic $L x r \alpha / \beta^{--}$mice had a trend towards increased urinary MDA compared with $\operatorname{Lxr} \alpha / \beta^{+/+}$mice

(Fig. 4j), suggesting that $L x r \alpha / \beta^{-/}$mice have an increased basal level of oxidative stress.

Treatment with an LXR agonist attenuated proteinuria and glomerular injury in diabetic DBA/2J mice To explore whether LXR activation could delay the onset of DN, we treated STZ-injected DBA/2J mice that were on a Western diet with vehicle or an LXR agonist for 10 weeks. We used DMHCA (instead of GW3965 or T091317) to avoid upregulation of hepatic SREBP1c and thus hypertriacylglycerolaemia and hepatic steatosis [25]. As anticipated, diabetic DBA/2J mice had twofold higher urinary ACR compared with non-diabetic mice, this increase being abolished with DMHCA (Fig. 5a). We measured urinary nephrin to assess podocyte integrity. There was a sixfold increase in nephrin excretion in STZ-treated $\mathrm{DBA} / 2 \mathrm{~J}$ mice compared with non-diabetic mice; this increase was reduced by $50 \%$ with DMHCA (Fig. 5b). To ensure that DMHCA was not activating other pharmacological targets, we studied STZ-injected $L x r \alpha / \beta^{-/}$mice on a Western $\operatorname{diet}$ (with or without DMHCA) for 14 weeks. As anticipated, the ACR was unchanged in $L x r \alpha / \beta^{-/-}$mice in response to DMHCA (Fig. 5c). In STZ DBA/2J mice, DMHCA improved the glomerular structure, decreasing mesangial expansion and reducing foam cell formation on PAS-stained sections (Fig. 5d). Although other LXR ligands have been implicated in repression of the renin-angiotensin system (RAS), we found no differences in renin or Ace expression in response to DMHCA (ESM Fig. 3b) or in STZ-treated $L x r \alpha / \beta^{-/}$mice compared with STZ $\operatorname{Lx} \alpha / \beta^{+/+}$mice (ESM Fig. 2b). Neither DMHCA nor loss of LXR $\alpha$ and LXR $\beta$ affected systolic blood pressure (ESM Fig. 4). Animals treated with DMHCA showed no significant change in glucose levels (Table 2), suggesting that the improvement in renal function was independent of hyperglycaemia.

Treatment with an LXR agonist decreased inflammation and lipid accumulation in kidneys of diabetic DBA/2J mice To assess inflammation in the DBA/2J model of diabetes, we examined inflammatory markers known to be dysregulated in DN. CD68 infiltration was markedly induced with diabetes and then attenuated in diabetic mice treated with DMHCA (Fig. 6a). Consistent with these results, the mRNA expression levels of Tlr2, Icam1, Opn and Cd68 were increased with diabetes and returned to non-diabetic levels upon DMHCA treatment (Fig. 6b-e). Furthermore, in diabetic mice treated with DMHCA, we found decreased Nox2 mRNA (Fig. 6f) and a significant decrease in levels of urinary MDA (Fig. 6g).

We next determined whether changes in neutral lipids correlated with the severity of DN in this animal model. Diabetic DBA/2J mice had increased glomerular Oil Red O staining, which was significantly attenuated with DMHCA (Fig. 7a). We explored pathways important to cholesterol efflux, synthesis and uptake, our aim being to determine 
Fig. 4 Diabetic $L x r \alpha / \beta^{-/}$mice have elevated proinflammatory and oxidative stress markers. (a) Immunostaining of infiltrating leucocytes with CD45 at $\times 400$ magnification. Veh, vehicle; WT, wild-type. (b) Quantification of CD45-positive cells per glomerulus in 25 glomeruli per mouse; $n=3-4$. (c) Kidney expression of genes encoding proinflammatory markers that are dysregulated in DN, i.e. Tlr2, (d) $I l 1 b$, (e) Icam-1 and (f) Opn, as well as (g) those expressing a macrophage marker $(\mathrm{Cd} 68)$ and $(\mathbf{h}, \mathbf{i})$ oxidative stress markers (Nox2 and $p 47^{\text {phox }}$ ). (j) Urinary MDA levels normalised to urinary creatinine. Data $(\mathbf{b}-\mathbf{j})$ are means \pm SEM; $n=6$, except for $L x r \alpha / \beta^{-/}(n=3)$ and CD45 quantification above (b); ${ }^{*} p<0.05$ compared with vehicle (V) control of the respective genotype and ${ }^{\dagger} p<0.05$ compared with $L x r \alpha / \beta^{+/+}$of the same treatment group, tests by oneway ANOVA and StudentNewman-Keuls
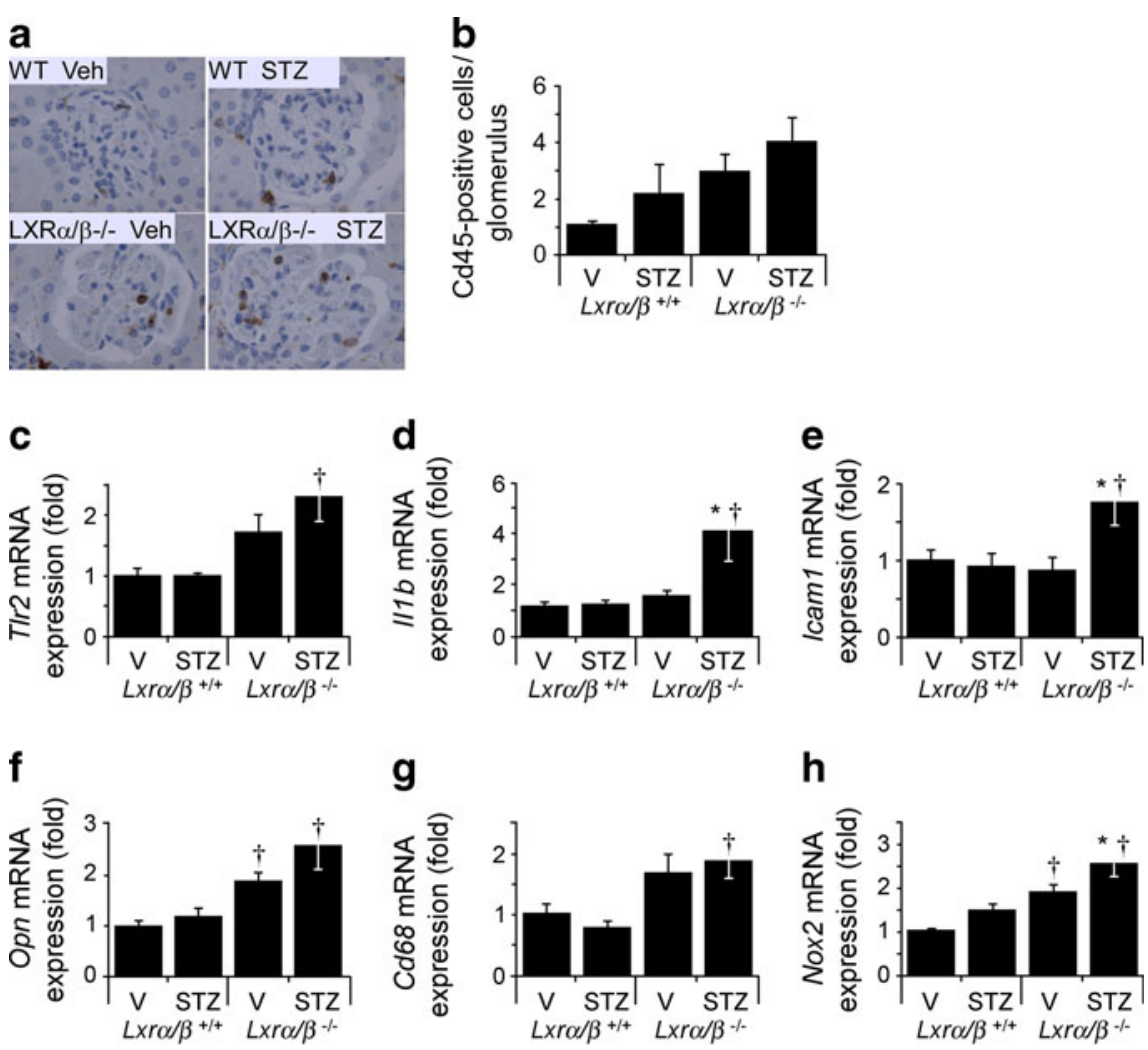

g

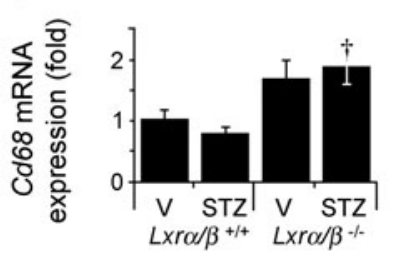

h
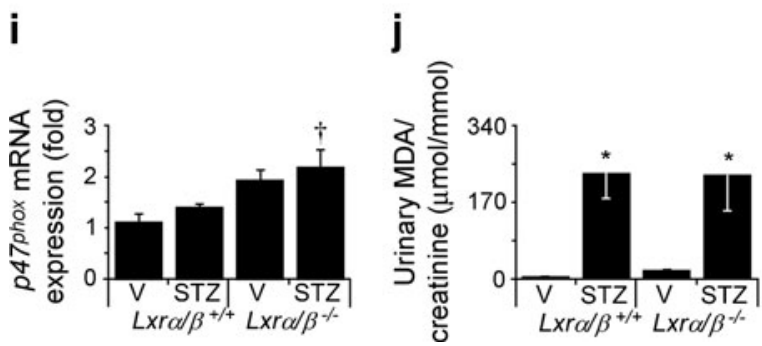

whether these could explain changes in renal cholesterol handling. Surprisingly, mRNA levels of Abcal and $A b c g 1$ were not significantly altered by DMHCA, but protein levels of ABCA1 tended to increase in DMHCA STZ mice (1.3-fold compared with vehicle-treated STZ) (ESM Fig. 3a, Fig. 7b). No significant differences in Hmgcr or Srebp 2 mRNA were observed (ESM Fig. 3a), while a trend towards increased Srebplc and Scdl (in the kidney) was observed only in non-diabetic animals (ESM Fig. 3a). Expression of Cd36 (mRNA) and Olr1 (mRNA and protein), which are both involved in ox-LDL uptake, were not changed during DMHCA treatment in STZ-treated mice (ESM Fig. 3b, c). To assess whether DMHCA acted directly at the kidney, we measured tissue drug levels by LC/MS/MS. DMHCA was detectable in STZ-treated mice, but not in non-diabetic mice, suggesting that DMHCA does indeed reach the kidney and that renal clearance of DMHCA is impaired with diabetes (Fig. 7c). The expression of $L x r \alpha$ was decreased with STZ and normalised to non-diabetic levels with DMHCA, with a similar trend being observed for $\operatorname{Lxr} \beta$ (Fig. 7d, e). Likewise, the LXR target gene Idol was increased with DMHCA in the kidney of STZ-injected mice (Fig. 7f), suggesting that lipoprotein uptake in the kidney may be decreased.

DMHCA significantly improved systemic lipid homeostasis Liver cholesterol content decreased $40 \%$ in mice treated with DMHCA compared with vehicle (Fig. 7g). In contrast to other LXR ligands, DMHCA also decreased liver triacylglycerol (Fig. 7h). These changes were supported by liver gene expression, with an increase in Cyp7a1 (which encodes a cholesterol metabolising enzyme) (Fig. 7i) and a decrease in the lipogenic gene Srebp1c (Fig. 7j), consistent with DMHCA being a gene-selective regulator of LXR. Remarkably, we observed a $48 \%$ decrease in plasma cholesterol and a $70 \%$ decrease in plasma triacylglycerol levels in DMHCA-treated vs vehicle-treated diabetic mice (Table 2). Together these data support a favourable role for LXR activation in mitigating the progression of DN through several mechanisms, including 

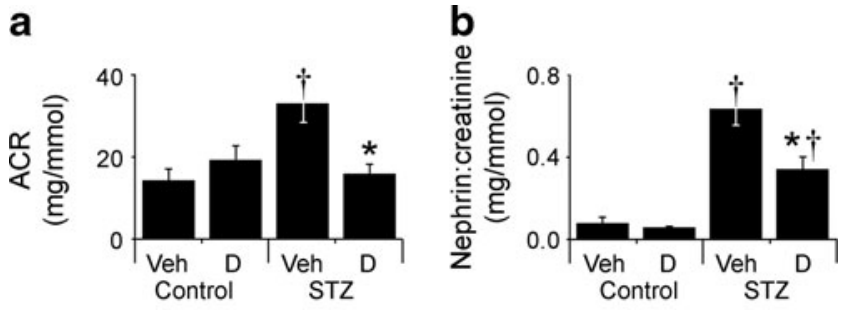

C
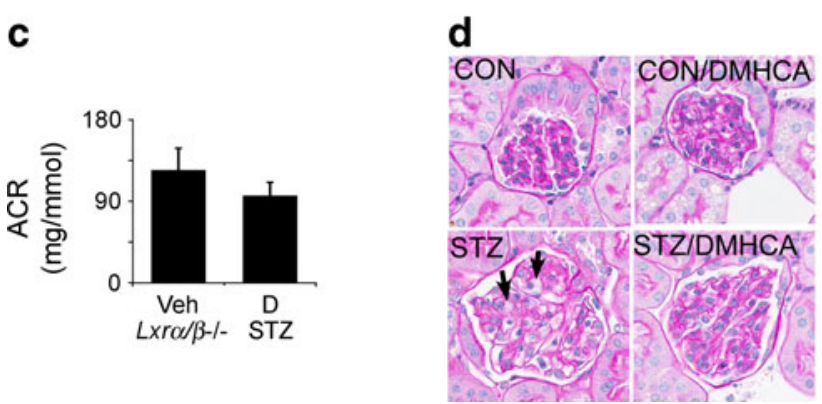

Fig. 5 LXR activation with DMHCA attenuates proteinuria and glomerular injury in diabetic DBA/2J mice. (a) Urinary ACR and (b) urinary nephrin:creatinine ratio after 10 weeks of control or STZ treatment with or without DMHCA (D) added to the diet. Veh, vehicle. (a) $n=4-8$, except for control DMHCA $(n=3)$; (b) $n=4-5$, except for control DMHCA $(n=3)$. Sample sizes were smaller for nephrin $(\mathbf{b})$ and for control DMHCA because insufficient spot urine was available from all mice. (c) Urinary ACR in $L x r \alpha / \beta^{-/-}$STZ mice on a diet with or without DMHCA for 14 weeks $(n=7-8)$. (d) PAS staining of representative kidney sections from $\mathrm{DBA} / 2 \mathrm{~J}$ mice at $\times 400$ magnification. Arrows point to foam-like cells. Data (a-c) represent means $\pm \mathrm{SEM}$; ${ }^{*} p<0.05$ for DMHCA vs the respective vehicle group and ${ }^{\dagger} p<0.05$ compared with the non-diabetic control group receiving the same treatment, tests by one-way ANOVA, Student-Newman-Keuls and (c) $t$ test

reduction of circulating plasma lipids, inhibition of glomerular lipid accumulation and suppression of inflammatory signalling and oxidative stress.

\section{Discussion}

New pharmacological targets are urgently needed to counteract progressive renal decline in patients with $\mathrm{DN}$. In the present study, we demonstrate that LXRs play an essential role in

\section{a}
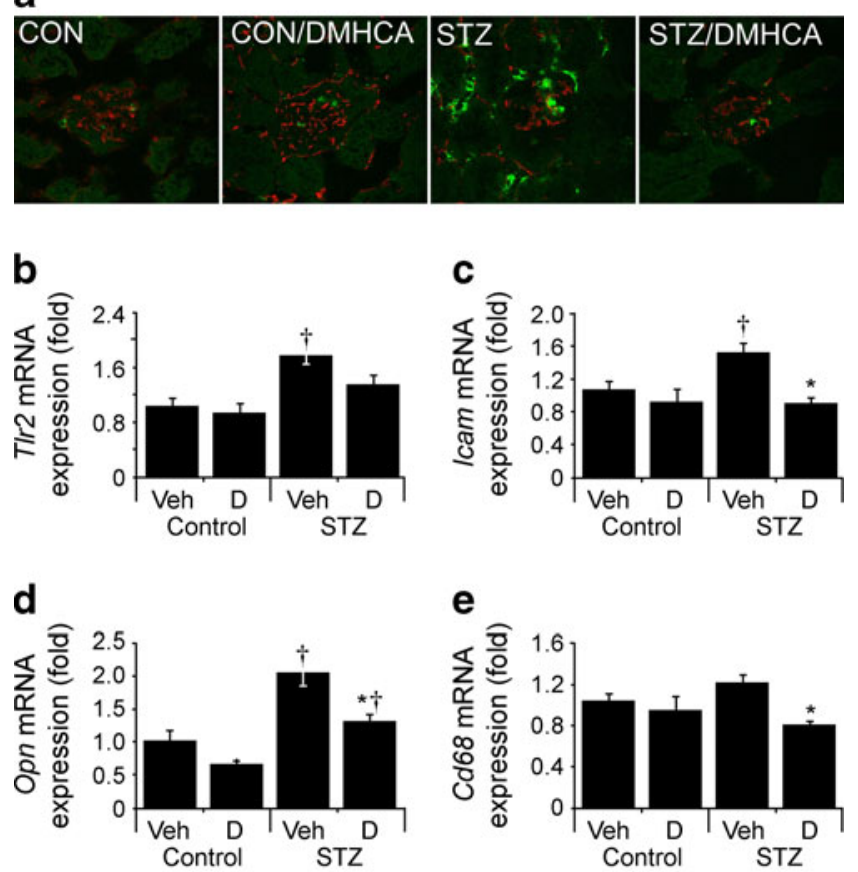

f

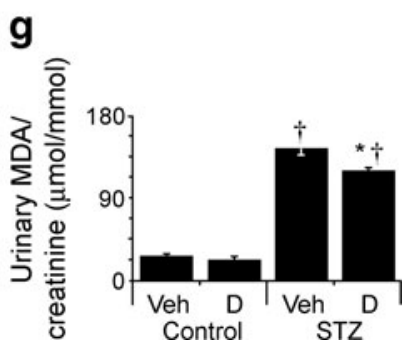

Fig. 6 LXR activation decreases inflammation in kidneys of diabetic $\mathrm{DBA} / 2 \mathrm{~J}$ mice. (a) Immunofluorescence staining of kidney sections for synaptopodin (red) and CD68 (green) at $\times 200$ magnification. (b) Gene expression analysis, in the kidney, of proinflammatory markers that are dysregulated in DN, e.g. Tlr 2, (c) Icam 1 and (d) Opn, as well as of (e) a macrophage marker $(\mathrm{Cd} 68)$ and (f) an oxidative stress marker (Nox2). (g) Urinary MDA levels normalised to creatinine content. D, DMHCA; Veh, vehicle. $(\mathbf{b}-\mathbf{g})$ Data are means \pm SEM; $n=4-8 ; * p<0.05$ for DMHCA vs the respective vehicle group and ${ }^{\dagger} p<0.05$ compared with the non-diabetic control group receiving the same treatment, tests by oneway ANOVA and Student-Newman-Keuls
Table 2 Physiological variables for non-diabetic and STZ-induced diabetic DBA/2J mice treated with the LXR agonist DMHCA

${ }^{*} p<0.05$ for difference from vehicle-treated animals of the same group

${ }^{\dagger} p<0.05$ for difference from controls of the same treatment group

\begin{tabular}{|c|c|c|c|c|}
\hline \multirow[t]{2}{*}{ Variable } & \multicolumn{2}{|l|}{ Control } & \multicolumn{2}{|l|}{ STZ } \\
\hline & Vehicle & DMHCA & Vehicle & DMHCA \\
\hline$n$ & 6 & 5 & 4 & 8 \\
\hline Body weight (g) & $42.1 \pm 0.6$ & $35 \pm 1^{*}$ & $23 \pm 1^{\dagger}$ & $21.6 \pm 0.6^{\dagger}$ \\
\hline Kidney weight (g) & $0.57 \pm 0.01$ & $0.54 \pm 0.02$ & $0.70 \pm 0.03^{\dagger}$ & $0.61 \pm 0.03^{*}$ \\
\hline Kidney:body weight ratio \% (g:g) & $1.36 \pm 0.03$ & $1.57 \pm 0.09$ & $3.0 \pm 0.1^{\dagger}$ & $2.83 \pm 0.09^{\dagger}$ \\
\hline Plasma glucose (mmol/l) & $10.2 \pm 0.7$ & $11 \pm 1$ & $45 \pm 3^{\dagger}$ & $50 \pm 3^{\dagger}$ \\
\hline Plasma triacylglycerol (mmol/l) & $6 \pm 1$ & $9 \pm 1$ & $30 \pm 8^{\dagger}$ & $9 \pm 3^{*}$ \\
\hline Plasma cholesterol (mmol/l) & $6.7 \pm 0.3$ & $4.5 \pm 0.2$ & $37 \pm 7^{\dagger}$ & $19 \pm 3 * *^{\dagger}$ \\
\hline
\end{tabular}


Fig. 7 LXR activation decreases glomerular lipid accumulation in kidneys of diabetic DBA/2J mice. (a) Oil Red O staining of kidney sections showing significant accumulation of neutral lipids in glomeruli of STZ mice, but not in those of DMHCA-treated STZ animals $(\times 100$ magnification). (b) Kidney protein abundance of ABCA1, a cholesterol efflux transporter. D, DMHCA; Veh, vehicle. (c) Intra-kidney levels of DMHCA as measured by LC/MS/MS. (d) Kidney gene expression of $L x r \alpha$, (e) $\operatorname{Lxr} \beta$ and (f) Idol. (g) Liver cholesterol and (h) triacylglycerol content was assayed after organic extraction and normalised to tissue weight. (i) Hepatic expression of Cyp7a1, which encodes the ratelimiting enzyme involved in the conversion of cholesterol to bile acids. Values determined by quantitative PCR. (j) Hepatic expression of Srebplc, which encodes a regulator of triacylglycerol synthesis. Values measured by quantitative PCR. Data $(\mathbf{b}-\mathbf{j})$ are means \pm SEM; $n=4-8$; ${ }^{*} p<0.05$ for DMHCA vs the respective vehicle group and ${ }^{\dagger} p<0.05$ compared with the non-diabetic control group receiving the same treatment, tests by one-way ANOVA and Student-Newman-Keuls

preserving renal structural and functional integrity under normal conditions and when challenged with diabetes. Experiments either in $L x r \alpha / \beta^{-/}$double knockout mice or using a novel next-generation LXR agonist revealed that LXRs ordinarily function to prevent intraglomerular lipid accumulation through differential uptake and/or retention of lipids. Our data specifically implicate the glomerulus (not tubular epithelial cells) as a primary target for dysfunction, which can be reversed with LXR activation. This is the first report on the in vivo significance of loss of LXR expression for renal filtration and underscores the protective role of LXRs in the prevention of DN.

$\operatorname{LXR} \alpha$ and LXR $\beta$ are involved in normal renal function with known actions on the RAS and high expression in the kidney [35, 36], including mesangial cells [37], glomerular endothelial cells and proximal tubular cells [38]. Previous studies have shown that activation of LXR with T091317 resulted in inhibition of isoprenaline-induced activation of RAS (without affecting blood pressure) [39], while treatment of angiotensin II-infused mice with GW3965 decreased expression of At1r (also known as Agtrap), Ace and renin, with a concomitant decrease in systolic blood pressure [40]. In our studies, we found that DMHCA treatment did not change renin or Ace expression, and LXR agonism or genetic knockout did not affect systolic BP. Therefore, the association we observed between glomerular lipid accumulation and other indices of diabetic renal injury are unlikely to be a consequence of LXR-mediated RAS-dependent actions, although these analyses need to be repeated with a larger cohort of mice.

Interestingly, our study uncovered a striking renal phenotype in $L x r \alpha / \beta^{-/}$mice, even without STZ, suggesting a critical homeostatic role for LXRs in kidney function. This was highlighted by the tenfold higher ACR in non-diabetic $L x r \alpha / \beta^{-/}$mice compared with $L x r \alpha / \beta^{+/+}$mice. Likewise, glomerular lipid accumulation and mesangial matrix expansion was increased in non-diabetic $L x r \alpha / \beta^{--}$mice compared with $L x r \alpha / \beta^{+/+}$mice. This new model of renal
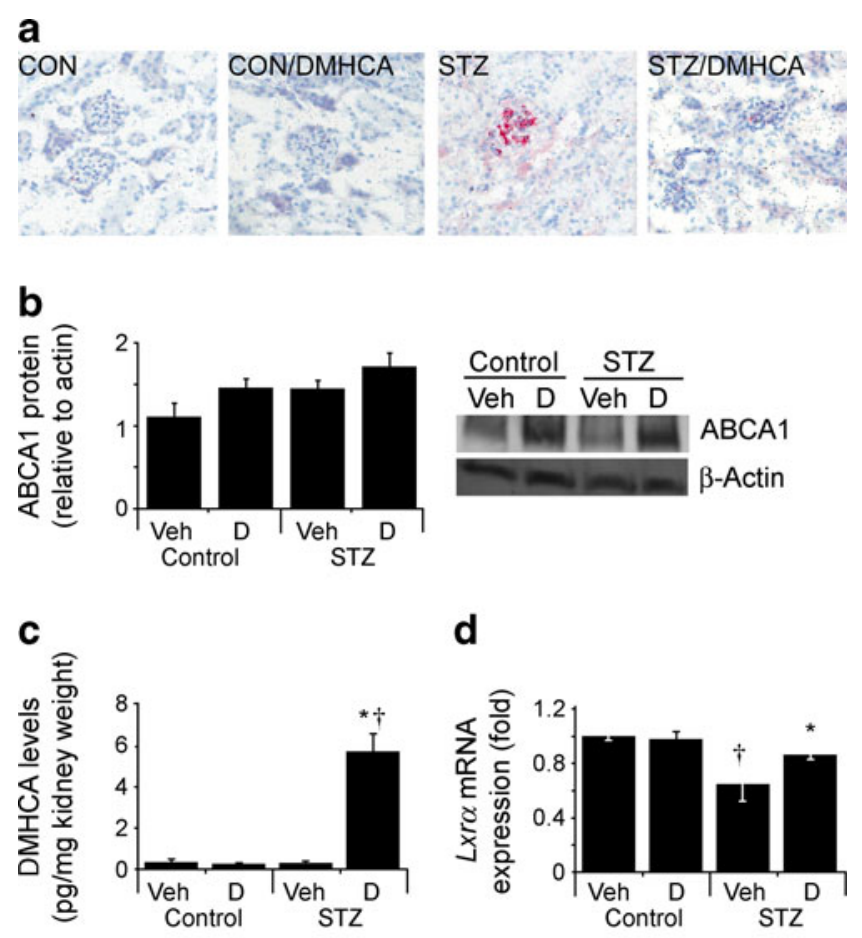

d
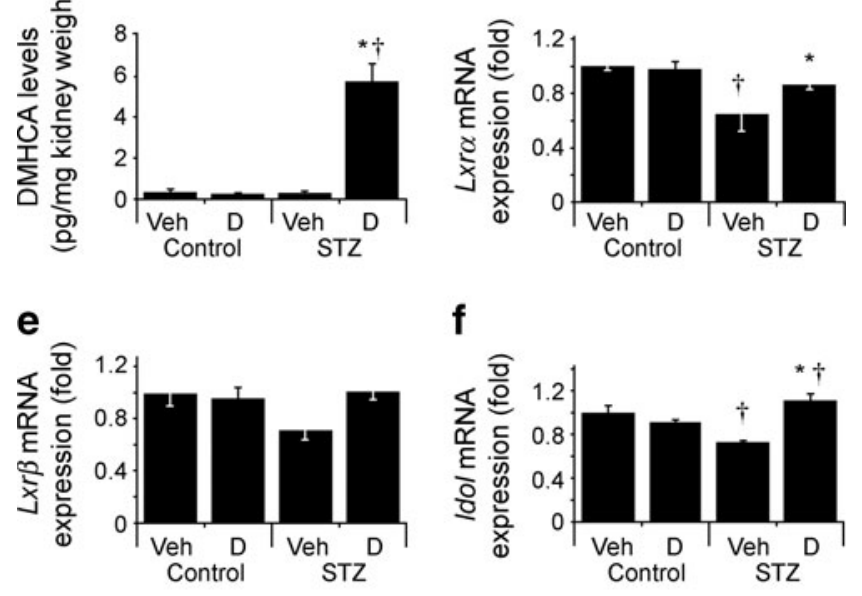

f
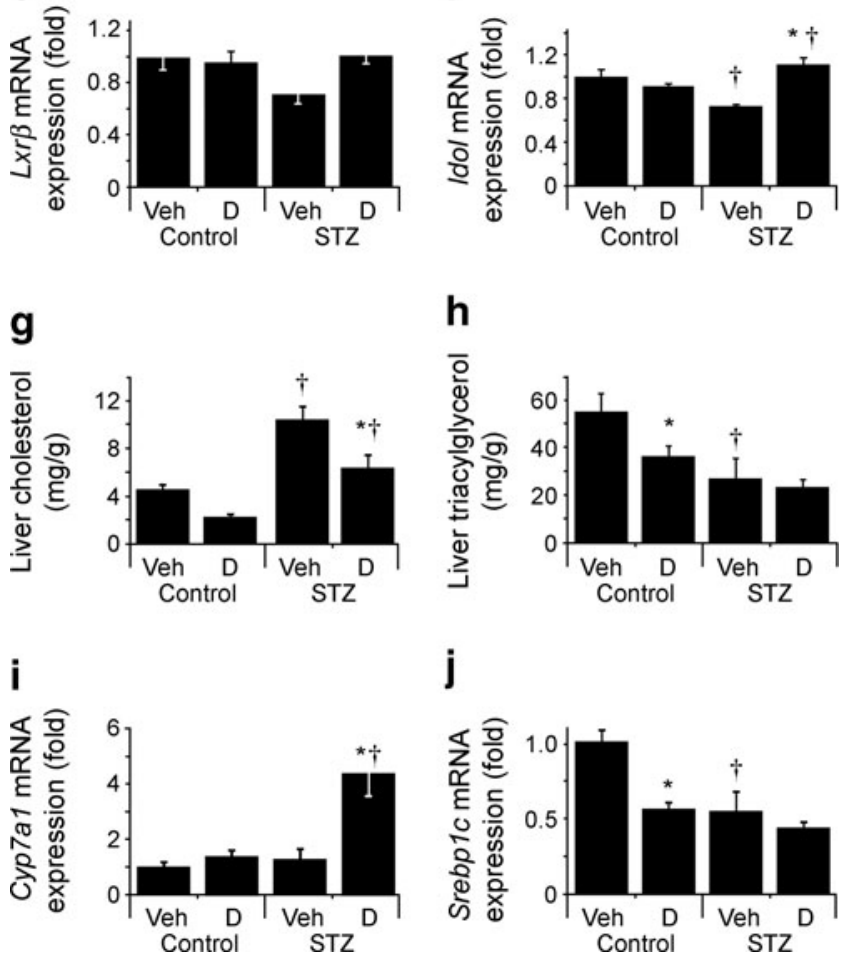

disease may be relevant to human disease, since the expression of $L X R \alpha$ and $L X R \beta$ is significantly decreased in patients with DN compared with controls [27] and renal biopsies from patients with DN show lipid deposition primarily in glomeruli [41-43]. Recent studies looking at LXR action in the kidney have shown improved albuminuria with other LXR ligands 
(T091317, GW3965) and different animal models of DN (STZ C57Bl/6, STZ $\left.L d l r^{-/}\right)$[28, 29]; however, these studies were unable to address the importance of LXR in baseline renal function. The authors attributed the improvement in renal function to inhibition of the proinflammatory gene osteopontin in renal tubular cells [29] or to enhanced activity of macrophage LXR $\alpha$ [28]. In contrast, our data, supported by loss of function and gain of function (using a gene-selective LXR ligand), suggest a more complex mechanism, which includes protection from lipid deposition in the glomerulus and inhibition of renal inflammation.

The reason for the preferential increase in glomerular lipids in diabetic $L x r \alpha / \beta^{--}$is still not clear. Oxidised-LDL has been previously shown to have a five- to tenfold greater affinity for uptake into mesangial cells than LDL [44]. We considered the possibility that ox-LDL may be more abundant in STZ-treated $L x r \alpha / \beta^{--}$mice, but found no significant difference in plasma ox-LDL between groups (Table 1). We also measured the uptake of fluorescently labelled ox-LDL in STZ $L x r \alpha / \beta^{--}$ and $L x r \alpha / \beta^{+/+}$kidneys, but found no difference at $30 \mathrm{~min}$ post infusion (data not shown). These data suggest that ox-LDL is not responsible for the glomerular lipid accumulation. Preferential uptake by the LDL receptor, a key lipoprotein carrier in the kidney [34], remains a plausible explanation. Alternatively, increased proteoglycan deposition as occurs in $\mathrm{DN}$ has also been recently shown to increase lipoprotein retention [45].

There are several limitations to our study. Gene expression analyses were performed on whole kidney, but greater changes might have been observed in isolated glomeruli, where the pathological state was primarily located. Our mice exhibited varying sensitivities to STZ, which left the number of animals in some groups lower than anticipated. We did not perform an exhaustive survey of the RAS; however, it is notable that $L x \mathrm{r} \alpha / \beta^{-/-}$mice have previously been shown to have a blunted response to isoprenaline, suggesting that $L x r \alpha / \beta^{-/}$mice would be protected against (not susceptible to) hypertension [46]. DMHCA was very effective at decreasing circulating cholesterol and triacylglycerol levels with additional beneficial effects on liver lipid levels. Therefore, despite the accumulation of DMHCA in the diabetic kidney, we cannot specifically define the contribution of renal vs systemic LXR activation to the improvement of DN. Nonetheless, cultured kidney mesangial cells treated with T0901317 showed increases in Abcal promoter activity and cholesterol efflux, suggesting that LXR is functional in this cell type and could contribute to the clearance of glomerular lipids [37]. Finally, due to the assessment of renal histology at a single time point, it is not clear whether glomerular lipids accumulate before or after the recruitment of inflammatory cells. Inflammatory cytokines can repress the expression of LXR and its target genes [47], and induce lipid accumulation [48], whereas lipids can induce the expression of inflammatory cytokines $[49,50]$. Thus, there is evidence supporting both scenarios. Regardless of the above, the activation of LXR is expected to inhibit both processes, suggesting it may be an ideal pharmacological target for DN.

In summary, our study highlights the importance of cholesterol homeostasis (independently of hyperglycaemia) in the development and severity of DN. In light of our findings, we propose that intraglomerular lipid accumulation will be more reflective of disease progression than plasma lipids. The data support the notion that (1) LXR plays an important basal role in the kidney and (2) pharmacological activation of LXR using a gene-selective agonist that does not cause hypertriacylglycerolaemia could be a novel approach to delaying the progression of $\mathrm{DN}$.

Acknowledgements We sincerely thank J. Scholey and G. Liu (University of Toronto, ON, Canada) for their advice and support, S. Quaggin, G. Fantus, D. Ng and P. Connelly (all University of Toronto) for contributions through discussion, D. Mangelsdorf (University of Texas Southwestern Medical Center, TX, USA) for providing the LXR-null mice, G. Sivaskandarajah (University of Toronto) for help with urinary protein assays, B. Bowskill (St. Michael's Hospital, Toronto, Canada) for blood pressure measurements, and C. Young (University of Toronto) for help with the ox-LDL in vivo study.

Funding Funding for the project was provided by the Kidney Foundation of Canada (to CLC), the Banting and Best Diabetes Centre (to CLC), the Canadian Institutes of Health Research (to MP), and NIH grants U01 DK076134 and NIH R01 AG026529 (both to ML).

Duality of interest The authors declare that there is no duality of interest associated with this manuscript.

Contribution statement MP, XW, AA, ML and CLC designed the experiments. MP, XW, RJ, LM, AR, RT, HS, WW and LQ acquired and analysed data. AO designed experiments and developed a critical reagent. All of the authors contributed to drafting the article or revising it critically for important intellectual content, and have given final approval of the version to be published.

\section{References}

1. U.S. Renal Data System (2012) USRDS 2012 annual data report: atlas of chronic kidney disease and end-stage renal disease in the United States. National Institutes of Health, National Institute of Diabetes and Digestive and Kidney Diseases, Bethesda

2. Bonnet F, Cooper ME (2000) Potential influence of lipids in diabetic nephropathy: insights from experimental data and clinical studies. Diabetes Metab 26:254-264

3. Diamond JR (1991) Analogous pathobiologic mechanisms in glomerulosclerosis and atherosclerosis. Kidney Int Suppl 31:S29S34

4. Keane WF, Kasiske BL, O'Donnell MP (1988) Lipids and progressive glomerulosclerosis. A model analogous to atherosclerosis. Am J Nephrol 8:261-271

5. Moorhead JF, Chan MK, El-Nahas M, Varghese Z (1982) Lipid nephrotoxicity in chronic progressive glomerular and tubulo-interstitial disease. Lancet 2:1309-1311

6. Orchard TJ, Chang YF, Ferrell RE, Petro N, Ellis DE (2002) Nephropathy in type 1 diabetes: a manifestation of insulin resistance and multiple genetic susceptibilities? Further evidence from the 
Pittsburgh Epidemiology of Diabetes Complication Study. Kidney Int 62:963-970

7. Hovind P, Tarnow L, Rossing P et al (2004) Predictors for the development of microalbuminuria and macroalbuminuria in patients with type 1 diabetes: inception cohort study. BMJ 328:1105

8. de Boer IH, Rue TC, Cleary PA et al (2011) Long-term renal outcomes of patients with type 1 diabetes mellitus and microalbuminuria: an analysis of the Diabetes Control and Complications Trial/Epidemiology of Diabetes Interventions and Complications cohort. Arch Intern Med 171:412-420

9. Jenkins AJ, Lyons TJ, Zheng D et al (2003) Lipoproteins in the DCCT/EDIC cohort: associations with diabetic nephropathy. Kidney Int 64:817-828

10. Morton J, Zoungas S, Li Q et al (2012) Low HDL cholesterol and the risk of diabetic nephropathy and retinopathy: results of the ADVANCE study. Diabetes Care 35:2201-2206

11. Wang XX, Jiang T, Shen Y et al (2011) Diabetic nephropathy is accelerated by farnesoid $\mathrm{X}$ receptor deficiency and inhibited by farnesoid $\mathrm{X}$ receptor activation in a type 1 diabetes model. Diabetes 59:2916-2927

12. Shevalye H, Lupachyk S, Watcho P et al (2012) Prediabetic nephropathy as an early consequence of the high-calorie/high-fat diet: relation to oxidative stress. Endocrinology 153:1152-1161

13. Yokoyama M, Tanigawa K, Murata T et al (2010) Dietary polyunsaturated fatty acids slow the progression of diabetic nephropathy in streptozotocin-induced diabetic rats. Nutr Res 30: 217-225

14. Onozato ML, Tojo A, Goto A, Fujita T (2004) Radical scavenging effect of gliclazide in diabetic rats fed with a high cholesterol diet. Kidney Int 65:951-960

15. Janowski BA, Willy PJ, Devi TR, Falck JR, Mangelsdorf DJ (1996) An oxysterol signalling pathway mediated by the nuclear receptor LXR alpha. Nature 383:728-731

16. Joseph SB, McKilligin E, Pei L et al (2002) Synthetic LXR ligand inhibits the development of atherosclerosis in mice. Proc Natl Acad Sci U S A 99:7604-7609

17. Zelcer N, Tontonoz P (2006) Liver X receptors as integrators of metabolic and inflammatory signaling. J Clin Invest 116:607-614

18. Zelcer N, Hong C, Boyadjian R, Tontonoz P (2009) LXR regulates cholesterol uptake through Idol-dependent ubiquitination of the LDL receptor. Science 325:100-104

19. Repa JJ, Mangelsdorf DJ (2002) The liver X receptor gene team: potential new players in atherosclerosis. Nat Med 8:1243-1248

20. Castrillo A, Joseph SB, Vaidya SA et al (2003) Crosstalk between LXR and toll-like receptor signaling mediates bacterial and viral antagonism of cholesterol metabolism. Mol Cell 12:805-816

21. Joseph SB, Bradley MN, Castrillo A et al (2004) LXR-dependent gene expression is important for macrophage survival and the innate immune response. Cell 119:299-309

22. Ogawa D, Stone JF, Takata Y et al (2005) Liver x receptor agonists inhibit cytokine-induced osteopontin expression in macrophages through interference with activator protein-1 signaling pathways. Circ Res 96:e59-e67

23. Repa JJ, Liang G, Ou J et al (2000) Regulation of mouse sterol regulatory element-binding protein-1c gene (SREBP-1c) by oxysterol receptors, LXRalpha and LXRbeta. Gene Dev 14:2819-2830

24. Quinet EM, Savio DA, Halpern AR, Chen L, Miller CP, Nambi P (2004) Gene-selective modulation by a synthetic oxysterol ligand of the liver X receptor. J Lipid Res 45:1929-1942

25. Kratzer A, Buchebner M, Pfeifer T et al (2009) Synthetic LXR agonist attenuates plaque formation in apoE-/- mice without inducing liver steatosis and hypertriglyceridemia. J Lipid Res 50:312-326

26. Proctor G, Jiang T, Iwahashi M, Wang Z, Li J, Levi M (2006) Regulation of renal fatty acid and cholesterol metabolism, inflammation, and fibrosis in Akita and OVE26 mice with type 1 diabetes. Diabetes 55:2502-2509
27. Martini S, Eichinger F, Nair V, Kretzler M (2008) Defining human diabetic nephropathy on the molecular level: integration of transcriptomic profiles with biological knowledge. Rev Endocr Metab Disord 9: 267-274

28. Kiss E, Kranzlin B, Wagenblabeta K et al (2013) Lipid droplet accumulation is associated with an increase in hyperglycemiainduced renal damage: prevention by liver X receptors. Am J Pathol 182:727-741

29. Tachibana H, Ogawa D, Matsushita Y et al (2012) Activation of liver $\mathrm{X}$ receptor inhibits osteopontin and ameliorates diabetic nephropathy. J Am Soc Nephrol 23:1835-1846

30. Patel R, Patel M, Tsai R et al (2011) LXRbeta is required for glucocorticoid-induced hyperglycemia and hepatosteatosis in mice. J Clin Invest 121:431-441

31. Breyer MD, Bottinger E, Brosius FC 3rd et al (2005) Mouse models of diabetic nephropathy. J Am Soc Nephrol 16:27-45

32. Brosius FC 3rd, Alpers CE, Bottinger EP et al (2009) Mouse models of diabetic nephropathy. J Am Soc Nephrol 20:2503-2512

33. Ruan XZ, Moorhead JF, Fernando R, Wheeler DC, Powis SH, Varghese Z (2004) Regulation of lipoprotein trafficking in the kidney: role of inflammatory mediators and transcription factors. Biochem Soc Trans 32:88-91

34. Xu ZE, Chen Y, Huang A et al (2011) Inflammatory stress exacerbates lipid-mediated renal injury in ApoE/CD36/SRA triple knockout mice. Am J Physiol Ren Physiol 301:F713-F722

35. Repa JJ, Mangelsdorf DJ (2000) The role of orphan nuclear receptors in the regulation of cholesterol homeostasis. Annu Rev Cell Dev Biol $16: 459-481$

36. Ruan XZ, Varghese Z, Powis SH, Moorhead JF (2005) Nuclear receptors and their coregulators in kidney. Kidney Int 68:2444-2461

37. Wu J, Zhang Y, Wang $\mathrm{N}$ et al (2004) Liver X receptor-alpha mediates cholesterol efflux in glomerular mesangial cells. Am J Physiol Ren Physiol 287:F886-F895

38. Zhang Y, Zhang X, Chen L et al (2006) Liver X receptor agonist TO901317 upregulates SCD1 expression in renal proximal straight tubule. Am J Physiol Ren Physiol 290:F1065-F1073

39. Kuipers I, van der Harst P, Kuipers F et al (2010) Activation of liver X receptor-alpha reduces activation of the renal and cardiac reninangiotensin-aldosterone system. Lab Investig J Tech Meth Pathol 90:630-636

40. Leik CE, Carson NL, Hennan JK et al (2007) GW3965, a synthetic liver $\mathrm{X}$ receptor (LXR) agonist, reduces angiotensin II-mediated pressor responses in Sprague-Dawley rats. Br J Pharmacol 151: $450-456$

41. Lee HS, Kim YS (1998) Identification of oxidized low density lipoprotein in human renal biopsies. Kidney Int 54:848-856

42. Lee HS, Lee JS, Koh HI, Ko KW (1991) Intraglomerular lipid deposition in routine biopsies. Clin Nephrol 36:67-75

43. Lee HS, Kruth HS (2003) Accumulation of cholesterol in the lesions of focal segmental glomerulosclerosis. Nephrol (Carlton) 8: 224-223

44. Coritsidis G, Rifici V, Gupta S et al (1991) Preferential binding of oxidized LDL to rat glomeruli in vivo and cultured mesangial cells in vitro. Kidney Int 39:858-866

45. Thompson J, Wilson P, Brandewie K et al (2011) Renal accumulation of biglycan and lipid retention accelerates diabetic nephropathy. Am J Pathol 179:1179-1187

46. Morello F, de Boer RA, Steffensen KR et al (2005) Liver X receptors alpha and beta regulate renin expression in vivo. J Clin Invest 115: 1913-1922

47. Wang Y, Moser AH, Shigenaga JK, Grunfeld C, Feingold KR (2005) Downregulation of liver $\mathrm{X}$ receptor-alpha in mouse kidney and HK-2 proximal tubular cells by LPS and cytokines. J Lipid Res 46:23772387

48. Ruan XZ, Varghese Z, Fernando R, Moorhead JF (1998) Cytokine regulation of low-density lipoprotein receptor gene 
transcription in human mesangial cells. Nephrol Dial Transplant 13: 1391-1397

49. Santini E, Lupi R, Baldi S et al (2008) Effects of different LDL particles on inflammatory molecules in human mesangial cells. Diabetologia 51:2117-2125
50. Massy ZA, Kim Y, Guijarro C, Kasiske BL, Keane WF, O'Donnell MP (2000) Low-density lipoprotein-induced expression of interleukin-6, a marker of human mesangial cell inflammation: effects of oxidation and modulation by lovastatin. Biochem Biophys Res Commun 267:536-540 